\title{
Resilience, sense of coherence and self-efficacy as predictors of stress coping style among university students
}

\author{
Karol Konaszewski $^{1}$ (D) $\cdot$ Marcin Kolemba ${ }^{1}$ Małgorzata Niesiobędzka ${ }^{1}$ \\ Published online: 16 July 2019 \\ (C) The Author(s) 2019
}

\begin{abstract}
The purpose of this study was to identify the personality predictors of individuals with a stress coping style. In the study, we have attempted to establish which traits play a crucial role in the prediction of tendencies applicable to a specific style of stress coping. In this study, all personality predictors were included in one model. The study was conducted with a group of 632 students. The results demonstrate a positive relationship between both self-efficacy and resilience with a task-oriented style of coping. Both traits related to a task-oriented style to a similar extent. The relationship between participants' sense of coherence and taskoriented style was non-significant. Participants' emotion-oriented style was negatively related with not just the sense of coherence variable, but also with self-efficacy and resilience. Significant predictors of avoidance-oriented styles were the sense of coherence and resilience variables. Further analysis of the two forms of avoidance-oriented styles demonstrate that the sense of coherence variable was a significant predictor of both engaging in substitute activities and seeking contact with other people. Resilience was a significant predictor solely with regard to seeking contact with other people.
\end{abstract}

Keywords Coping $\cdot$ Resilience $\cdot$ Sense of coherence $\cdot$ Self-efficacy

\section{Introduction}

Difficult situations happen in everyone's life. The ability to cope with them is a vital competence that should be developed. Lazarus and Folkman, in their relational theory of stress coping, perceive it as a dynamic process aimed at sufficient management of external and internal demands that are appraised by individuals as taxing or exceeding their resources (Lazarus and Folkman 1984). Hence, researchers distinguish stress coping (1) that is focused on a problem, i.e. facing a situation, and (2) focused on emotions, which entails the application of such strategies as self-distancing, avoidance/escape, self-blame, looking for support, or re-appraisal. Based on the above assumptions, Endler and Parker (1990a, 1990b, 1994) conceived the process of handling stress and distinguished three basic styles of stress coping: task-oriented, emotion-oriented and avoidance-oriented. The first one involves undertaking tasks and making an effort in order to solve a problem through cognitive transformations, or attempting to change a situation, mainly by planning and focusing on a task.

Karol Konaszewski

k.konaszewski@uwb.edu.pl; karolkonaszewski@wp.pl

1 Faculty of Pedagogy and Psychology, University of Bialystok, Świerkowa 20, 15-328 Białystok, Poland
The second one is connected with a tendency to focus on oneself, one's own emotions (e.g. anger, feelings of guilt), wishful thinking and fantasizing. A purpose of such behaviour is to reduce emotional tension connected with a stressful situation. However, it may sometimes strengthen stress, increase tension or evoke depression. The last type - avoidance - involves a tendency to refrain from thinking about, experiencing and facing a stressful situation. The style focused on avoidance may take two forms: becoming engaged in substitute activities (e.g. watching TV, overeating or sleeping) or looking for social contacts (Endler and Parker 1990a, 1994).

The present study concerns personal predictors of the style applied by university students to manage stress. It is focused on three individual traits: resilience, sense of coherence and self-efficacy. They make up everyone's set of resources that help in facing life's difficulties and stressful situations efficiently and adapting to ever changing reality.

\section{Resilience and Stress Coping}

Theoretical assumptions and empirical findings show that resilience can be variously conceptualized. Resilience might be seen as a personality characteristic, as a positive, distinct feature of an individual that prevents negative effects of stress and minimizes episodes of depression (Wagnild and Young 
1993; Wagnild 2009a; Catalano et al. 2011; Bonanno et al. 2012). In this approach resilience represents a constellation of characteristics that enable individuals to adapt to the circumstances they encounter (Connor and Davidson 2003). Resilience has been conceptualized also as a 'dynamic process encompassing positive adaptation within the context of significant adversity' (Luthar et al. 2000, p. 543), a process that changes over time (Fletcher and Sarkar 2013). Resilience is also recognized as a competence, as the capacity to handle significant changes and to increase responsibility by rebounding from adversity, uncertainty and negative, or even positive, changes. It is a positive, developable capacity that changes over time (Stewart et al. 1997; Luthans 2002; Magnano et al. 2016).

In this study, we conceptualize resilience as a relatively stable personal resource, being a positive personality characteristic that can be activated or used as personal competence and acceptance of self and life, all of which facilitates personal adaptation, i.e. coping with change or misfortune (Wagnild 2009b). Wagnild and Young (1990; Wagnild, 2014) identified five personality characteristics that make up resilience: equanimity, meaningfulness, perseverance, self-reliance and existential aloneness. Equanimity is a balanced perspective of life and experiences and might be viewed as sitting loose and taking what comes, thus moderating the extreme responses to adversity. Meaningfulness is the realization that life has a purpose and the recognition that there is something to live for. Perseverance is the ability to keep going despite setbacks. Those who are self-reliant believe in themselves; they recognize and rely on their personal strengths and capabilities, and draw upon past successes to support and perhaps guide their actions. And finally, existential aloneness is the realization that each person is unique and that while some experiences can be shared, others must be faced alone (Wagnild and Young 1990, 1993).

Resilience correlated negatively with stress (Chen et al. 2017; Costa et al. 2017; Smith and Yang 2017). Scarce research carried out so far has shown a positive relation between resilience and task-oriented coping strategies and a negative one between emotion-oriented strategies in a group of American students. The research has not included avoidance because researchers assumed that this coping style is heterogeneous (an adaptive style combined with a maladaptive one) (Campbell-Sills et al. 2006). Similar results have been obtained in research on 17-18 year-old school students who survived an earthquake in L'Aquila, in Italy. The research confirmed a positive relation between resilience and a taskoriented style (Dumont and Provost 1999; Stratta et al. 2013) and a negative one with regard to an emotion-oriented style (Stratta et al. 2013). A relation between resilience and avoidance has not been found (Stratta et al. 2013). Among patients with post-traumatic stress disorder (PTSD), this study showed positive correlations between resilience and active coping strategies, such as problem solving, cognitive restructuring or social support seeking, and negative correlations with avoidant coping strategies, such as problem avoidance and social withdrawal (Thompson et al. 2018). Significant predictors of both resilience and coping strategies are attachment styles (Craparo et al. 2018). The data demonstrated that secure adult attachment connects positively with the ability to modulate affects, and through alexithymia links indirectly to positive coping and resilience (Craparo et al. 2018). On the basis of the results obtained by previous researchers, we may anticipate a positive relation between resilience and a task-oriented style, and a negative one with regard to an emotion-oriented style. Moreover, we expect no relation between resilience and avoidance.

\section{Sense of Coherence and Stress Coping}

Antonovsky (1987) emphasized that a crucial construct that helps to understand how an individual deals with stress and remains healthy is a sense of coherence (SOC). People whose sense of coherence is high are able to evaluate the surrounding world properly. They also know that the challenges they encounter are worth work and effort. They respond to a stressor actively believing that the resources they have are valuable and will allow them to overcome difficulties. Sense of coherence (SOC) enhances a person's ability to handle daily stressors, and people with high SOC are able to avoid stressors. Hochwälder and Saied (2018) demonstrated that university students with high SOC experienced fewer daily hassles than students with low SOC and also experienced the hassles as less stressful.

The research demonstrates a positive relation between sense of coherence and task-oriented style as well (Cohen et al. 2008; Cohen and Dekel 2000; Krok 2016). Pallant and Lae (2002) indicated that individuals whose sense of coherence is high more often respond to stressors by applying problem-oriented strategies such as planning, positive reinterpretation of a situation, or active conduct focused on a problem. Opposite to the task-oriented style, the relation between sense of coherence and emotion-oriented style is negative (Cohen et al. 2008; Krok 2016). Nahlen and Saboonchi (2010) indicated that the lower the sense of coherence, the higher the tendency to apply emotion-oriented strategies such as venting or self-blame. As far as avoidance is concerned, research outcomes are less univocal. Some research demonstrates a negative relation between avoidance and sense of coherence (Cohen et al. 2008; Cohen and Dekel 2000) but data demonstrating positive relations between sense of coherence and avoidance-oriented coping appear as well (Krok 2016). Taking the results of the above research into consideration, we may anticipate a positive relation between sense of coherence and a task-oriented style of stress coping, and a negative relation between an emotions-oriented style and avoidance-oriented coping. 


\section{Self-Efficacy and Stress Coping}

Self-efficacy is defined as one's general belief in one's efficacy in managing difficult situations and obstacles (Jerusalem and Schwarzer 1992). Bandura (1997) defines self-efficacy as a strong belief that one is able to achieve designated aims or accomplish specific tasks. General self-efficacy (GSE) is a component of one's personal resources affecting the appraisal of abilities to face challenges generated by a given stressor. Even though there are few studies analysing the relations between self-efficacy and styles of stress coping, available data suggest positive relations between self-efficacy and the problem-oriented style of stress coping and negative relations with the emotion-oriented style. The research of secondary school Chinese teachers has revealed that self-efficacy correlates positively with active strategies of stress coping and positive thinking (Shen 2009). Similar results were obtained in other groups (Chwalisz et al. 1992; Parto and Besharat 2011). Furthermore, the research demonstrates a negative relation between self-efficacy and emotion-oriented strategies of stress coping (Chwalisz et al. 1992; Dahlbeck and Lightsey Jr 2008). Based on the outcomes of the above research, we may anticipate a positive relation between self-efficacy and taskoriented style of stress coping and a negative relation with emotion-oriented style. We further assume that a relation between self-efficacy and avoidance-oriented style will be negative because a low self-efficacy entails the appraisal of a stress generating factor as a threat rather than a challenge.

\section{The Current Study}

The purpose of the study was to find out the personality predictors of a stress coping style used by university students. Our study is focused on three personality characteristics: resilience, a sense of coherence and self-efficacy. What is more, in our study we have attempted to establish which trait plays a crucial role in the prediction of tendencies to apply a specific style of stress coping. This was possible because in contrast to previous analyses, in our study all personality predictors were included in one model, thanks to which their relative importance in the prediction of distinct styles of stress coping could be established.

\section{Method}

\section{Participants}

632 students aged between 19 and $25(M=21.96 ; S D=1.67)$ took part in the study. Most respondents were female $(N=$ 551). The sample consisted of students of pedagogy $(N=$ 266), economics and management $(N=83)$, law and criminology $(N=79)$, social work $(N=69)$, philology $(N=56)$, sociology and history $(N=43)$, biology and chemistry $(N=$ $19)$ and informatics and mathematics $(N=17)$. The research project was approved by the Ethics Committee of the Faculty of Pedagogy and Psychology at the University of Bialystok. The study was conducted through direct contact with respondents and via the Internet. Some students received a research sheet in paper form directly from the researcher, who explained the purpose of the study, informing the respondents about their voluntary consent to take part in it and withdraw at any time. The respondents who took part in the study via the Internet received emails with the above information. All participants gave a written consent in compliance with the Helsinki Declaration.

\section{Materials and Procedure}

Stress Coping The Coping Inventory for Stressful Situations CISS (Endler and Parker 1990a, 1990b) in the Polish version adapted by Strelau et al. (2005) has been applied to measure strategies of stress coping. The scale contains 48 items. It allows to measure three basic styles of coping with a stressful situation: 1) task-oriented style (T), which assumes a deliberate and decisive focus on solving a problem and an attempt at changing a situation that is perceived as stressful, 2) emotionoriented style (E), which comprises emotional responses such as self-absorption, fantasizing and self-blame, and 3) avoidance-oriented style (A), which assumes an activity focused on avoiding a problem, escaping from a problem without attempting to solve it. Avoidance style may take two forms - distraction (D), i.e. attempts at separating from a situation by undertaking another type of activity, becoming engaged in a substitute activity, or social diversion (SD) - seeking contact with other people. Using a 5 -degree scale $(1-$ never, 2 - very seldom, 3 - sometimes, 4 - often, 5 - very often), respondents estimated how often they engage in specific action when they encounter difficult stressful situations. The Polish version of the CISS had shown a good internal consistency - Cronbach's alpha (.65-.90), in 16-24 age group: T: $\alpha=.90$; E: $\alpha=.89$; A: $\alpha=.81$ (D: $\alpha=.77$; SD: $\alpha=.72$ ); in $25-54$ age group: T: $\alpha=.89$; E: $\alpha=.89 ; \mathrm{A}: \alpha=.80$ (D: $\alpha=.77$; SD: $\alpha=.74$ ); in 55-79 age group: T: $\alpha=.84$; E: $\alpha=.86$; $\mathrm{A}: \alpha=.78$ (D: $\alpha=.71$; SD: $\alpha=.65$ ) (Strelau et al. 2005).

Resilience Resilience was measured by the Resilience Scale RS-14 (Wagnild and Young 1993). The authors of the Scale defined resilience as a personality characteristic which supports the process of adaptation in difficult situations. The Polish adaptation was made by Surzykiewicz et al. (2019). The scale consists of 14 items. All items were assessed on a 7-point scale from 1 - I do not agree, to 7 - I agree. The Polish version of the RS-14 had shown test-retest a very good reliability (.88) and a good internal consistency $(\alpha=.85)$ (Surzykiewicz et al. 2019). 
Self-Efficacy Self-efficacy was measured by Schwarzer and Jerusalem's Generalized Self-Efficacy Scale - GSES (1993). The scale is made up of 10 statements to assess perceived selfefficacy regarding coping and adaptation abilities in daily activities and stressful situations (Schwarzer 1993). The Polish adaptation was made by Schwarzer, Jerusalem and Juczyński (Juczyński 2012). Participants indicated for each statement how true it is for them $(1-$ not at all true, $2-$ hardly true, 3 - moderately true, 4 - exactly true). The Polish version of the GSES had shown test-retest an acceptable reliability (.78) and a good internal consistency - Cronbach's alpha (.85) (Juczyński 2012).

Sense of Coherence Sense of coherence was measured by Antonovsky (1993) (SOC-13), in the Polish adaptation by Dudek and Makowska (1993). The scale consists of 13 statements. Respondents answer with the use of a 7-point Likert scale, where " 1 " means that a given attitude always occurs while "7" means it never happens. The Polish version of the SOC-13 had shown a very good the internal consistency coefficients (Cronbach's alpha) ranged from .81 to .91 (Dudek and Makowska 1993).

\section{Factor Structure and Reliability of the Measures}

Confirmatory factor analysis (CFA) with maximum likelihood (ML) estimation in AMOS 24 and Cronbach's alpha coefficient in SPSS 24 was applied to verify the factor structure of the measures. A range of goodness-of-fit statistics and the appropriateness of the model parameters evaluated the overall model fit. The chi-square statistic assesses the sample and implied covariance matrix; a good fitting model is indicated by a non-significant result. The chi-square statistic is, however, strongly associated with sample size, and as such good models tend to be over-rejected. The comparative fit index (CFI) and the Tucker-Lewis index (TLI) are measures of how much better the model fits the data compared to a baseline model where all variables are uncorrelated. For these indices, values above .95 indicate a good model fit but values above .90 are considered acceptable (Bentler, 1990; Hu and Bentler 1999). The root-mean-square error of approximation (RMSEA) is also presented. Ideally these indices should be less than .05 , but values less than .08 are considered acceptable (Bentler, 1990; Hu and Bentler 1999). The convergent validity was assessed by the Average Variance Extracted (AVE) and Composite Reliability (CR). AVE values above .70 are considered very good, and the level of .50 is acceptable. The acceptable value of CR is .70 and above. Furthermore, when AVE value is less than .50 but CR is higher than .60, the convergent validity of the construct is still adequate (Fornell and Larcker 1981).

In CFA of the Coping Inventory for Stressful Situations (CISS), both three- ( $\mathrm{T}$, task-oriented style; E, emotion- oriented style; A, avoidance-oriented style) and four-factor (T; E; D, engaging in substitute activities; SD, seeking contact with other people) solutions were examined. The three-factor model did not provide a good approximation of the data based on chi-square, CFI and TLI statistics. Further inspection of the RMSEA revealed that this statistic was acceptable and approached the criteria for a good model fit: $\chi^{2}(1077)=$ 4682.00; $p<.001 ; \chi^{2} / d f=4.34 ;$ RMSEA = .073 (low = .071; high $=.075) ; \mathrm{TLI}=.68 ; \mathrm{CFI}=.70$. The four-factor model was found to provide a better fit of the data than the three-factor model: $\chi^{2}(882)=2220.88 ; p<.001 ; \chi^{2} / d f=2.51$; RMSEA $=.049($ low $=.047$; high $=.052)$; TLI = .87; $\mathrm{CFI}=.88$. In this study, the reliability (Cronbach's alpha) of the sub-scales was found to be as follows: T: $\alpha=.89$; E: $\alpha=.89 ; \mathrm{A}: \alpha=.81$ (D: $\alpha=.77$; SD: $\alpha=.81$ ). AVE values were between 0.32 and 0.51 (T: .42; E: .43; A: .32 (D: .40; SD: .50), but CR values were acceptable (T: .91; E: .90; A: .84 (D: .83; SD: .85) and thus the convergent validity of the CISS dimensions was adequate (Fornell and Larcker 1981).

Next we conducted CFA of the 14-item Resilience Scale (RS-14). The results showed a good fit of the one-factor model to empirical data: $\chi^{2}(70)=264.87 ; p<.001 ; \chi^{2} / d f=3.78$; RMSEA $=.066($ low $=.058 ;$ high $=.075) ;$ TLI $=.91$; $\mathrm{CFI}=.93$; the reliability of the RS-14 measured with Cronbach's alpha was good $(\alpha=.87)$, AVE was .40 , but CR was acceptable .90. Furthermore, the one-factor model of the General Self-Efficacy Scale (GSES) was well fitted to empirical data: $\chi^{2}(34)=76.97 ; p<.001 ; \chi^{2} / d f=2.26$; RMSEA $=.045($ low $=.031 ;$ high $=.058]) ;$ TLI $=.97$; $\mathrm{CFI}=.98$; the reliability of the GSES was $\operatorname{good}(\alpha=.87)$, AVE was .50 and CR .90. With CFA of the 13-item Sense of Coherence Scale (SOC-13), the results showed a good fit of the one-factor model to empirical data: $\chi^{2}(60)=197.96$, $p<.001 ; \chi^{2} / d f=3.29 ;$ RMSEA $=.060$ (low $=.051 ;$ high $=$ $.070) ; \mathrm{TLI}=.92 ; \mathrm{CFI}=.94$; the reliability of the SOC-13 was good $(\alpha=.82)$. AVE was .40 , but CR was acceptable .86 , and thus the convergent validity of the SOC was adequate (Fornell and Larcker 1981).

\section{Results}

Table 1 presents descriptive statistics and bivariate correlations between personality characteristics and styles of stress coping. The correlation analysis has revealed significant mutual relationships among personality characteristics. The correlation between resilience and sense of coherence was significant, positive and strong $(r=.56, p=.001)$. A positive and very strong, relationship was also noted between self-efficacy and resilience $(r=.71, p=.001)$. Furthermore, the relation between sense of coherence and self-efficacy was significant too $(r=.52, p=.001)$. We have also noticed mutual relations among the styles of stress coping used by students. The 
relations between emotion-oriented style and avoidanceoriented style $(r=.28, p=.01)$ was moderate and positive, while the relation between task-oriented style and emotionoriented style $(r=-.21, p=.01)$ turned out to be moderate and negative. The relation between task-oriented style and avoidance style was weak and positive $(r=.12, p=.01)$. Moreover, the correlation analysis revealed a significant positive relation between resilience and task-oriented style $(r=.57, p=.001)$ as well as a negative one with emotionoriented style $(r=-.51, p=.001)$. The relation between resilience and avoidance-oriented style was insignificant $(r=.05$, $p=.145$ ). We have also noticed a positive relation between sense of coherence and task-oriented style $(r=.38, p=.001)$ and a negative relation with emotion-oriented style $(r=-.62$, $p=.001$ ) while no significant relation with avoidance-oriented style $(r=-.03, p=.348)$ has been found. Self-efficacy was significantly and positively related to task-oriented style $(r=.58, p=.001)$ and negatively with emotion-oriented style $(r=-.50, p=.001)$. The relation between self-efficacy and avoidance-oriented style was insignificant $(r=.05, p=.197)$ (Table 1). To identify multicollinearity between variables the Variance Inflation Factor (VIF) was used. Small VIF values, ranged from 1.542 to 2.293 , did not indicate serious multicollinearity symptomps.

Next, structural equations modelling was applied to verify the hypotheses. The relations between resilience, a sense of coherence, self-efficacy and three stress coping styles were analysed with the use of the AMOS 22 program. The stress coping styles have been introduced to the model as observable

Table 1 Means (M), standard deviations (SD), reliabilities $(\alpha)$ and intercorrelations - resilience, sense of coherence, self-efficacy and stress coping styles

\begin{tabular}{lllllll}
\hline & RS & SOC & GSES & T & E & A \\
\hline SOC & $.56^{* *}$ & & & & & \\
GSES & $.71^{* *}$ & $.52^{* *}$ & & & & \\
T & $.57^{* *}$ & $.38^{* *}$ & $.58^{* *}$ & & & \\
E & $-.51^{* *}$ & $-.62^{* *}$ & $-.50^{* *}$ & $-.21^{* *}$ & & \\
A & .05 & -.03 & .05 & $.12^{* *}$ & $.28^{* *}$ & \\
M & 72.59 & 50.62 & 30.02 & 58.28 & 48.51 & 48.58 \\
SD & 11.94 & 11.49 & 4.81 & 9.22 & 12.01 & 10.30 \\
$\alpha$ & .87 & .82 & .87 & .89 & .89 & .81 \\
$\alpha$ men group & .87 & .83 & .88 & .90 & .89 & .83 \\
$\alpha$ women group & .88 & .76 & .87 & .88 & .89 & .79 \\
\hline
\end{tabular}

$\alpha=$ Cronbach's alpha

${ }^{* *}$ Correlation is significant at the 0.01 level (2-tailed)

$\mathrm{T}$ - stress coping style focused on a task; E - stress coping style focused on emotions; A - stress coping style focused on avoidance; SOC - sense of coherence; RS - resilience; GSES - generalized sense of self-efficacy

Per Cohen (1992), the absolute value of a correlation is equivalent to its effect size, with those under 0.10 being trivial and those between 0.10 and 0.30 being small//weak variables. Due to the relations between the analysed variables that had been established earlier, apart from the regression paths necessary to test the predictive value of variables, we supplemented the model with co-variances amongst sense of coherence, resilience and self-efficacy as well as a covariance amongst an avoidance-oriented style, emotion-oriented style and task-oriented style. The model parameters have been estimated with the use of maximum likelihood method. GFI (goodness-of-fit index), CFI (comparative-fit-index), RMSEA (root-mean-square error of approximation) and Chi-squared variables $\left(\chi^{2} / d f\right)$ have been applied to assess the goodness of model fit to the data. The values of GFI $\geq .90$ and $\mathrm{CFI} \geq .95$ indicate good and adequate model fit to the data ( $\mathrm{Hu}$ and Bentler 1999). The values of $\chi^{2} / d f<2$ also suggest good model fit to the data. The values of RMSEA $<.08$ may also be interpreted as good fit to the data (Brown 2015; Byrne 2016; Kline 2015).

The tested model appears to fit the data very well $\chi^{2}(2)=$ $0.99 ; p=0.608 ; \chi^{2} / d f=0.49 ;$ RMSEA $=0.000[\mathrm{LO}=0.000$; $\mathrm{HI}=0.064] ; \mathrm{GFI}=0.99 ; \mathrm{AGFI}=0.99 ; \mathrm{CFI}=1.00$. Selfefficacy $(\beta=.35, p<.001)$ and resilience $(\beta=.33, p<.001)$ were significant predictors of a propensity for using taskoriented style in the group of students. In turn, resilience $(\beta=.12, p<.05)$ and sense of coherence $(\beta=-.11, p<.05)$ were significant predictors of propensity for using avoidance-oriented style. Nevertheless, the relation between resilience and avoidance-oriented style was weak and positive while that with sense of coherence was weak and negative. On the other hand, all tested traits were significant predictors of propensity for using emotion-oriented style. This style related negatively with sense of coherence $(\beta=-.46, p<.001)$, selfefficacy $(\beta=-.18, p<.001)$ and resilience $(\beta=-.12, p<.01)$. The relation between sense of coherence and task-oriented style was insignificant, similar to the relation between selfefficacy and avoidance-oriented style. That is why these relations have been removed from the final model. Figure 1 presents standard path indicators: standard regression indicators for one-way arrows and correlation indicators for two-way arrows. Sense of coherence, resilience and self-efficacy altogether explained $39 \%$ of task-oriented style variances and $44 \%$ of emotion-oriented style variances. With regard to avoidance-oriented style, the level of explained variance amounted merely to $1 \%$.

In the next step another SEM model was tested. In the second model, an avoidance-oriented style was divided into two forms: becoming engaged in substitute activities (D) and seeking contact with other people (SD). This model also appeared to be a very good fit to the data $\chi^{2}(5)=2.42 ; p=0.787$; $\chi 2 / d f=0.48 ;$ RMSEA $=0.000[\mathrm{LO}=0.000-\mathrm{HI}=0.036]$; $\mathrm{GFI}=0.99 ; \mathrm{AGFI}=0.99 ; \mathrm{CFI}=1.00$.

Figure 2 presents a standardized model. The results demonstrate that sense of coherence is a significant predictor of both the extent of engaging in substitute activities (D) and 
Fig. 1 The first structural model $(N=632)$. Note. Factor loadings are standardized. Sense of coherence, resilience and generalized sense of self-efficacy vs. stress coping styles: task-oriented, emotion-oriented and avoidance-oriented. T - taskoriented style; E - emotionoriented style; A - avoidanceoriented style; SOC - sense of coherence; RS - resilience; GSES - generalized sense of selfefficacy

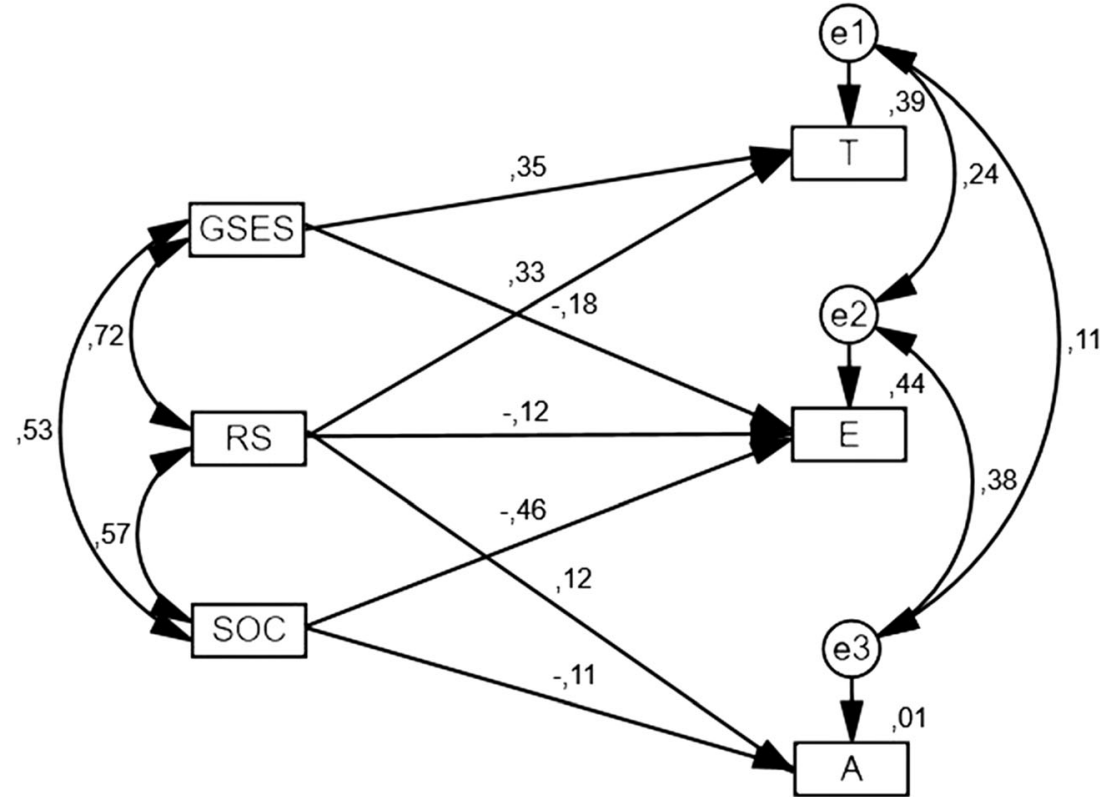

seeking contact with other people (SD). In the first case, this relation was negative $(\beta=-.21, p<.001)$ while in the second one - positive $(\beta=.10, p<.01)$. Moreover, resilience was a significant predictor of the extent of seeking contact with other people $(\beta=.29, p<.001)$. The relation between self-efficacy and engaging in substitute activities and the extent of seeking contact with other people was insignificant. That is why these relations were removed from the final model. In the second model, the explained variance for emotion-oriented style amounted to $44 \%$ and $39 \%$ for task-oriented style, respectively; SD variance was explained in $12 \%$ while $\mathrm{D}$ variance in $4 \%$.

We also decided to test a second model for samples of men and women due to significant differences in willingness to use coping styles between these groups. Student's $t$ test revealed a significant effect for emotion-oriented style $[t(630)=2.30$, $p<.05]$, engaging in substitute activities $[t(630)=2.70$, $p<.01]$ and seeking contact with other people $[t(630)=$ $5.10, p<.001]$. Women were more likely than men to use both avoidance-oriented style and emotion-oriented style. In the
Fig. 2 The second structural model $(\mathrm{N}=632)$. Note. Factor loadings are standardized. Sense of coherence, resilience and generalized sense of self-efficacy vs. stress coping styles: focus on a task, focus on emotions, engaging in substitute activities, and seeking contact with other people. T task-oriented style; E - emotionoriented style; D - engaging in substitute activities; SD- seeking contact with other people; SOC sense of coherence; RS - resilience; GSES - generalized sense of self-efficacy

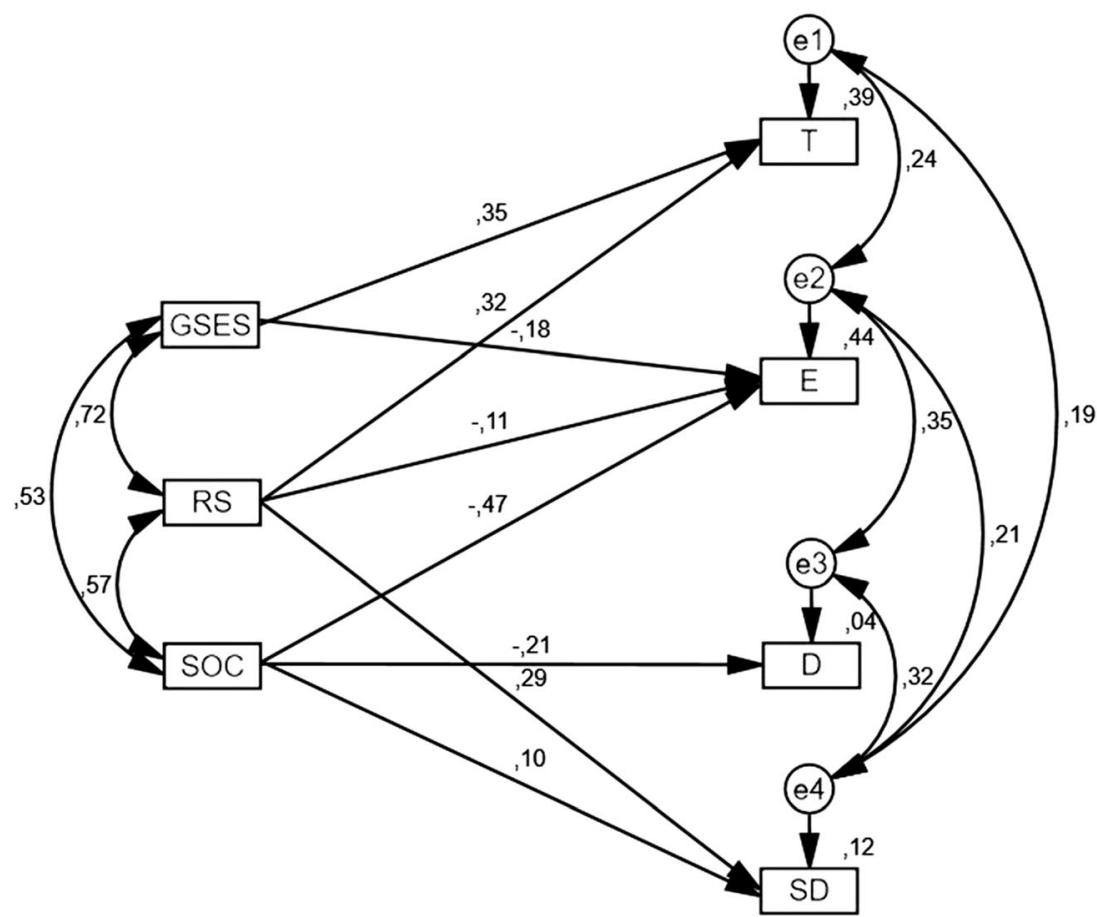


sample of women, the tested model appeared to fit the data very well: $\chi^{2}(5)=3.18 ; p=.672 ; \chi^{2} / d f=.63$; RMSEA $=.001$ $($ low $=.001 ;$ high = .046); goodness-of-fit index $(\mathrm{GFI})=.99$; adjusted GFI $(\mathrm{AGFI})=.99 ; \mathrm{CFI}=1.00$. All tested variables were significant predictors of propensity for using emotionoriented style. This style related negatively with SOC $(\beta=$ $-.47, p<.001)$, self-efficacy $(\beta=-.17, p<.001)$ and resilience $(\beta=-.12, p<.01)$. Self-efficacy $(\beta=.34, p<.001)$ and resilience $(\beta=.32, p<.001)$ were significant positive predictors of a propensity for using task-oriented style. However, SOC was a significant predictor of both the extent of engaging in substitute activities (D) and seeking contact with other people (SD): for D this relation was negative $(\beta=-.20, p<.001)$, whereas for SD it was positive $(\beta=.13, p<.01)$. Moreover, resilience was a significant predictor of the extent of seeking contact with other people $(\beta=.27, p<.001)$. Together, SOC, resilience and self-efficacy explained $37 \%$ of task-oriented style variance and $44 \%$ of emotion-oriented style variance. Distraction variance was explained in $4 \%$ and variance in seeking contact with other people in $12 \%$. Figure 3 presents a standardized model in the sample of women.

In the sample of men, the tested model again appeared to fit the data very well: $\chi^{2}(7)=4.18 ; p=0.758 ; \chi^{2} / d f=.59$; RMSEA $=.001 \quad($ low $=.001 ;$ high $=.096) ;$ GFI $=.98$; AGFI $=.94 ; \mathrm{CFI}=1.00$. Self-efficacy $(\beta=.32, p<.01)$ and resilience $(\beta=.43, p<.001)$ were significant predictors of a propensity for using task-oriented style. Emotion-oriented style related negatively with SOC $(\beta=-.48, p<.001)$ and self-efficacy $(\beta=-.26, p<.01)$. The extent of engaging in substitute activities related negatively with $\operatorname{SOC}(\beta=-.26$, $p<.05)$. In turn, the extent of seeking contact with other people connected positively with resilience $(\beta=.38, p<.001)$. The relation between resilience and emotion-oriented style, as well as between SOC and seeking contact with other people, was non-significant. Together, SOC, resilience and selfefficacy explained $50 \%$ of task-oriented style variance and $42 \%$ of emotion-oriented style variance. Distraction variance was explained in $7 \%$ and variance in seeking contact with other people in $15 \%$. Figure 4 presents a standardized model in the sample of men.

\section{Discussion}

The purpose of the study was to determine personality predictors of stress coping styles in the group of university students. It is worth emphasizing that in contrast to previous analyses, in our study all personality predictors were included in one model, thanks to which their relative significance in predicting stress coping styles could be established. The analysis of results indicates a significant role of personality resources in stress management. The obtained data have demonstrated a positive relation of self-efficacy and resilience with taskoriented style (Campbell-Sills et al. 2006; Parto and Besharat 2011; Shen 2009; Stratta et al. 2013). Both traits related to task-oriented style to a similar extent. With regard to the results of previous research (Cohen et al. 2008; Cohen and Dekel 2000; Krok 2016; Pallant and Lae 2002), a lack of relation between sense of coherence and task-oriented style came as a complete surprise. On the other hand, as expected
Fig. 3 The third structural model $(N=551)$ in women group. Note. Factor loadings are standardized. Sense of coherence, resilience and generalized sense of self-efficacy vs. stress coping styles: focus on a task, focus on emotions, engaging in substitute activities, and seeking contact with other people. T task-oriented style; E - emotionoriented style; D - engaging in substitute activities; SD- seeking contact with other people; SOC sense of coherence; RS - resilience; GSES - generalized sense of self-efficacy

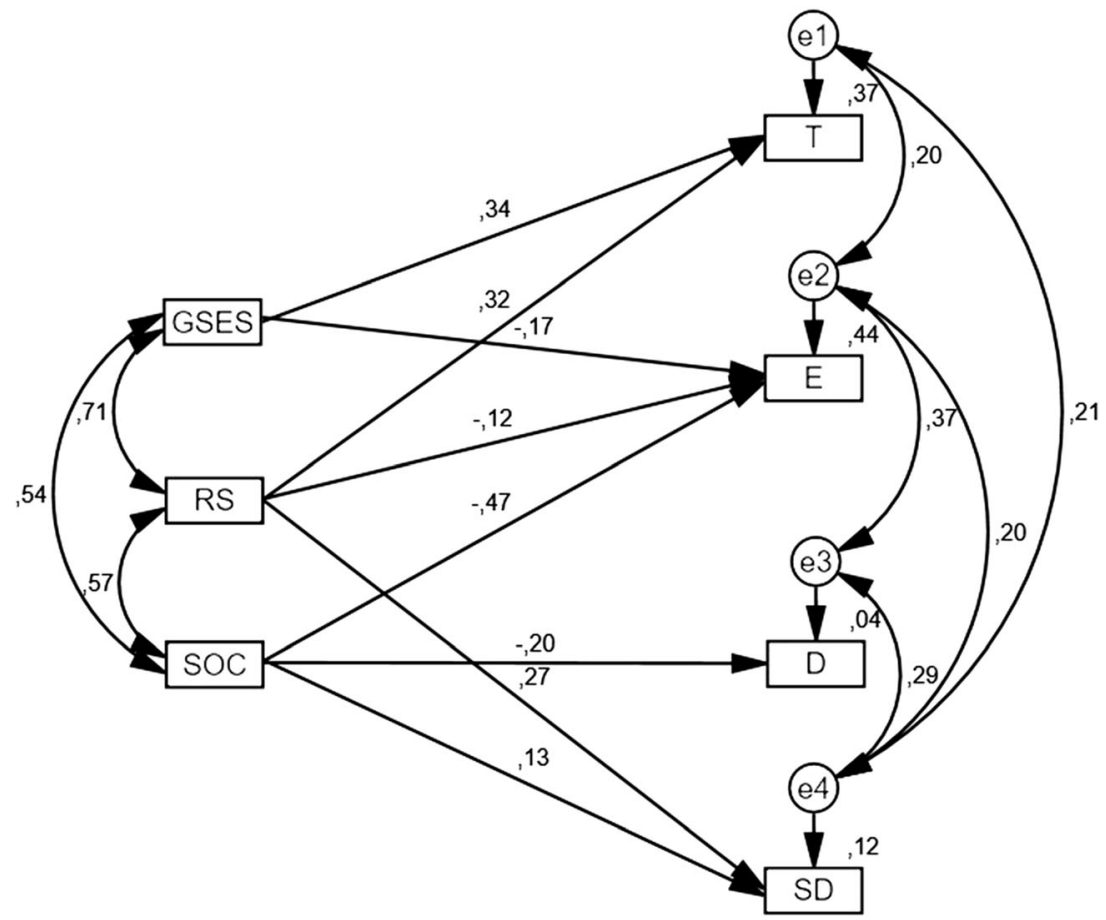


Fig. 4 The fourth structural model $(N=81)$ in men group. Note. Factor loadings are standardized. Sense of coherence, resilience and generalized sense of self-efficacy vs. stress coping styles: focus on a task, focus on emotions, engaging in substitute activities, and seeking contact with other people. T - taskoriented style; E - emotionoriented style; D - engaging in substitute activities; SD- seeking contact with other people; SOC sense of coherence; RS - resilience; GSES - generalized sense of self-efficacy

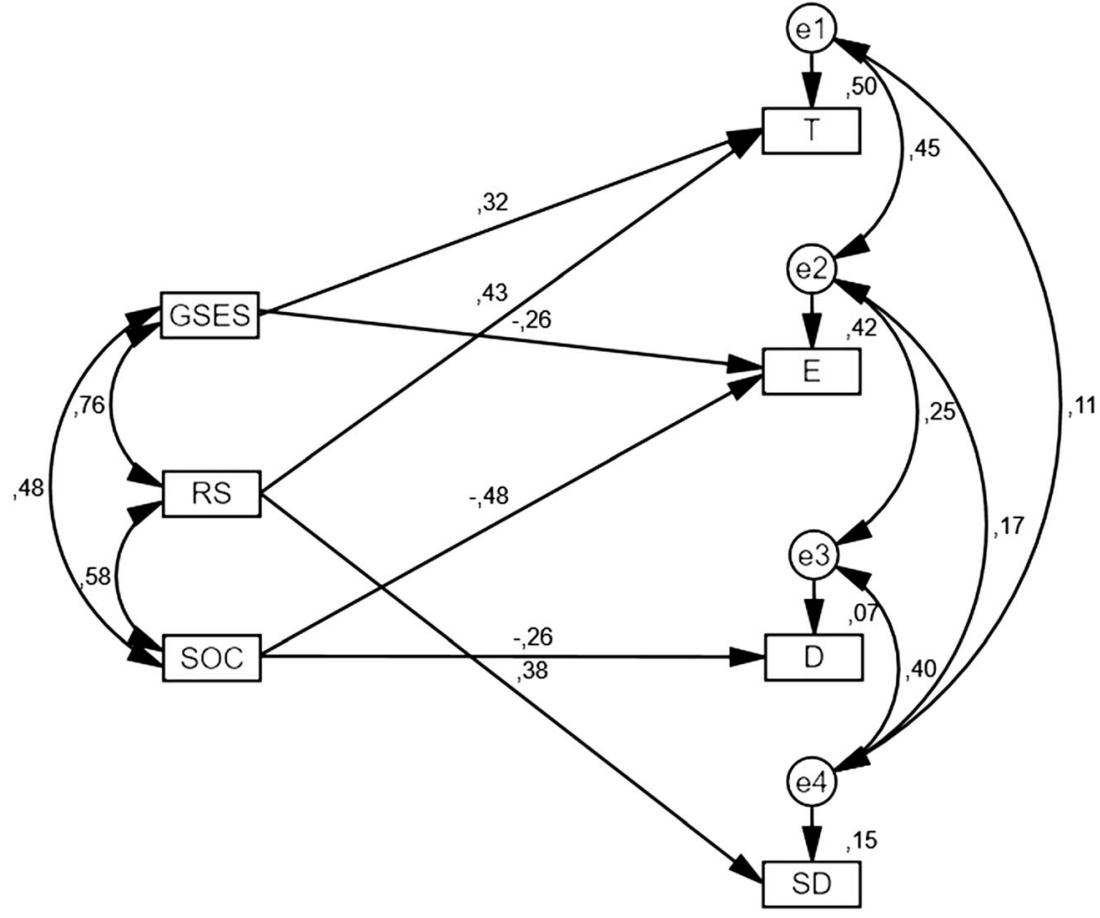

and in accordance with earlier findings, stress coping style that is emotion-oriented related negatively with both sense of coherence, self-efficacy and resilience (Cohen et al. 2008; Dahlbeck and Lightsey Jr 2008; Krok 2016; Nahlen and Saboonchi 2010; Stratta et al. 2013). The results of the study indicate that sense of coherence is the strongest predictor of emotion-oriented style in the group of university students. What is more, sense of coherence related significantly negatively with avoidance-oriented style. Similar to Krok's research (2016), resilience was also a significant, yet positive, predictor of avoidance-oriented style. In the study, the relations shared by avoidance-oriented style and personality characteristics have been analysed more precisely. First of all, due to the two-factor structure of the avoidance-oriented sub-scale and a low level of explained variance for this style, in the next step we tested a model where avoidance-oriented style was divided into two forms: engaging in substitute activities and seeking contact with other people. Sense of coherence was a significant predictor of both engaging in substitute activities and seeking contact with other people. It is worth noticing that the relations of both types of avoidance-oriented style were distinct: the relation was always negative with regard to engaging in substitute activities and positive in the case of seeking contact with other people. Resilience, on the other hand, was a significant predictor solely with regard to seeking contact with other people.

The results of this study have demonstrated that women and men manage their stress in very different ways. Women scored significantly higher than men on the emotional coping style. The data confirmed earlier findings suggesting that women's coping style is more emotion-focused than that of men (Ptacek et al. 1994; Tamres et al. 2002; Matud 2004; Kelly et al. 2008; Brougham et al. 2009). In this study women also were more likely than men to use two forms of avoidance coping style. Similar results have been demonstrated by Ptacek et al. (1994), Diehl et al. (1996) and Tamres et al. (2002). Structural equation modelling indicated which predictors of coping style were significant in male and female group. Self-efficacy and resilience were significant predictors of taskoriented style in both groups; however, in female group both personality characteristics had a similar positive impact, whereas in male resilience was the more important predictor. With regard to emotion-oriented style, SOC was the strongest predictor in both groups. All three personality characteristics related negatively with emotion-oriented style in female group but not in male, except for SOC, only self-efficacy had impact. All three personality characteristics related negatively with emotion-oriented style in the women but in the men, except for SOC, only self-efficacy had impact. Seeking contact with other people related purely and simply with resilience in the group of men. In turn, in the group of women this coping style also related positively with SOC. Furthermore, SOC related negatively with engaging in substitute activities in both groups. The relation between resilience, self-efficacy and engaging in substitute activities was non-significant. These results should be treated with caution due to the number of participants in the group of men. However, we point out that there are not only gender differences in our sample in the tendency to use particular styles of coping, but also that gender moderates the relationship between personality 
characteristics and coping. The latter findings require further analysis and research.

The present study depicts the significance of specific personality characteristics and designates directions for working on the process of stress management among university students. The study results belong to the contemporary trend of describing resources in the categories of personality disposition - a relatively stable feature that helps to overcome life difficulties and stressful situations effectively and allows adaptation to changing reality. In accordance with the study results, resilience and self-efficacy are the factors which may determine the choice of a meaningful way of coping with stressful situations in the group of students. If we assume that supporting an individual in harmonious development is a priority, it is worth beginning with developing resources which foster adaptive coping with stressful situations. Effective stress coping with the help of adaptive strategies plays a crucial role in effective functioning and significantly affects young adults' well-being.

The present study has some limitations. The majority of the sample were women; men constituted merely about $13 \%$. Furthermore, the design of the study was correlational, so no causal conclusions can be reached. Thus, the results of the study should be interpreted with caution. Despite these limitations, the present study demonstrated which personality characteristics may be included as the most significant predictors of particular stress coping styles in the group of students. The novelty of the study is to employ an approach that combines the examination of the impact of resilience, sense of coherence and self-efficacy in one model, which made it possible to determine the relative importance of each trait in predicting the particular coping style usage. Moreover, in the study, the relations between avoidance-oriented style and personality characteristics have been analysed not only generally, but also with division into two forms: engaging in substitute activities and seeking contact with other people. In the study we focused on resilience, sense of coherence and self-efficacy. Future studies should extend the examined model and introduce other personality characteristics to it, e.g. hardiness, locus of control or ego-resiliency.

\section{Conclusion}

The present study provides insights into personal determinants of stress coping strategies used by university students. The study demonstrated the significant role of personality resources in coping stress style usage. The obtained data indicated that all three traits were responsible for emotion-oriented style usage, but mainly sense of coherence. In turn, selfefficacy and resilience strongly and positively connected with task-oriented style. Another important result of the present study concerns the predictors of avoidance-oriented style in the group of students. More detailed analysis revealed that two forms of this style did not relate to self-efficacy. Seeking contact with other people was positively connected especially with resilience, and also with sense of coherence but to a lesser extent. Engaging in substitute activities was connected only with sense of coherence, and this relationship was negative.

Funding This work was supported by the National Science Centre, Poland, [grant number: 2015/17/N/HS6/02900].

\section{Compliance with Ethical Standards}

Ethical Approval All procedures performed in studies involving human participants were in accordance with the ethical standards of the institutional and/or national research committee and with the 1964 Helsinki declaration and its later amendments or comparable ethical standards.

Conflict of Interest On behalf of all the authors, the corresponding author states that there is no conflict of interest.

Informed Consent The study was carried out in accordance with the recommendations of Declaration of Helsinki and local ethical guidelines for studies with human participants with written informed consent from all subjects. The protocol for the study was approved by Research Ethics Committee at the Faculty of Pedagogy and Psychology of the University of Bialystok.

Open Access This article is distributed under the terms of the Creative Commons Attribution 4.0 International License (http:// creativecommons.org/licenses/by/4.0/), which permits unrestricted use, distribution, and reproduction in any medium, provided you give appropriate credit to the original author(s) and the source, provide a link to the Creative Commons license, and indicate if changes were made.

\section{References}

Antonovsky, A. (1987). Unraveling the mystery of health: How people manage stress and stay well. Jossey-bass.

Antonovsky, A. (1993). The structure and properties of the sense of coherence scale. Social Science \& Medicine, 36(6), 725-733. https:// doi.org/10.1016/0277-9536(93)90033-Z.

Bandura, A. (1997). Self-efficacy: The exercise of control. Macmillan.

Bentler, P.M. (1990) Comparative Fit Indexes in Structural Models. Psychological Bulletin, 107, 238-246. https://doi.org/10.1037/ 0033-2909.107.2.238.

Bonanno, G. A., Kennedy, P., Galatzer-Levy, I. R., Lude, P., \& Elfström, M. L. (2012). Trajectories of resilience, depression, and anxiety following spinal cord injury. Rehabilitation Psychology, 57(3), 236-247. https://doi.org/10.1037/a0029256.

Brougham, R. R., Zail, C. M., Mendoza, C. M., \& Miller, J. R. (2009). Stress, sex differences, and coping strategies among college students. Current Psychology, 28(2), 85-97. https://doi.org/10.1007/ s12144-009-9047-0.

Brown, T. A. (2015). Confirmatory factor analysis for applied research. Guilford Publications.

Byrne, B. M. (2016). Structural equation modeling with AMOS: Basic concepts, applications, and programming. Third Edition: Routledge.

Campbell-Sills, L., Cohan, S. L., \& Stein, M. B. (2006). Relationship of resilience to personality, coping, and psychiatric symptoms in young 
adults. Behaviour Research and Therapy, 44(4), 585-599. https:// doi.org/10.1016/j.brat.2005.05.001.

Catalano, D., Chan, F., Wilson, L., Chiu, C. Y., \& Muller, V. R. (2011). The buffering effect of resilience on depression among individuals with spinal cord injury: A structural equation model. Rehabilitation Psychology, 56(3), 200-211. https://doi.org/10.1037/a0024571.

Chen, Y., McCabe, B., \& Hyatt, D. (2017). Impact of individual resilience and safety climate on safety performance and psychological stress of construction workers: A case study of the Ontario construction industry. Journal of Safety Research, 61, 167-176. https://doi.org/10. 1016/j.jsr.2017.02.014.

Chwalisz, K., Altmaier, E. M., \& Russell, D. W. (1992). Causal attributions, self-efficacy cognitions, and coping with stress. Journal of Social and Clinical Psychology, 11(4), 377-400. https://doi.org/10. 1521/jscp.1992.11.4.377.

Cohen, J. (1992). A power primer. Psychological Bulletin, 112(1), 155159

Cohen, M., Ben-Zur, H., \& Rosenfeld, M. J. (2008). Sense of coherence, coping strategies, and test anxiety as predictors of test performance among college students. International Journal of Stress Management, 15(3), 289-303. https://doi.org/10.1037/1072-5245. 15.3.289.

Cohen, O., \& Dekel, R. (2000). Sense of coherence, ways of coping, and well being of married and divorced mothers. Contemporary Family Therapy, 22(4), 467-486.

Connor, K. M., \& Davidson, J. R. (2003). Development of a new resilience scale: The Connor-Davidson resilience scale (CD-RISC). Depression and Anxiety, 18(2), 76-82. https://doi.org/10.1002/da. 10113.

Costa, A. L. S., Heitkemper, M. M., Alencar, G. P., Damiani, L. P., da Silva, R. M., \& Jarrett, M. E. (2017). Social support is a predictor of lower stress and higher quality of life and resilience in Brazilian patients with colorectal cancer. Cancer Nursing, 40(5), 352-360. https://doi.org/10.1097/NCC.0000000000000388.

Craparo, G., Magnano, P., Zapparrata, M. V., Gori, A., Costanzo, G., Pace, U., \& Pellerone, M. (2018). Coping, attachment style and resilience: The mediating role of alexithymia. Mediterranean Journal of Clinical Psychology, 6(1) ISSN: 2282-1619.

Dahlbeck, D. T., \& Lightsey, O. R., Jr. (2008). Generalized self-efficacy, coping, and self-esteem as predictors of psychological adjustment among children with disabilities or chronic illnesses. Children's Health Care, 37(4), 293-315. https://doi.org/10.1080/ 02739610802437509 .

Diehl, M., Coyle, N., \& Labouvie-Vief, G. (1996). Age and sex differences in strategies of coping and defense across the life span. Psychology and Aging, 11(1), 127-139.

Dudek, B., \& Makowska, Z. (1993). Psychometric characteristics of the orientation to life questionnaire for measuring the sense of coherence. Polish Psychological Bulletin, 24(4), 309-318.

Dumont, M., \& Provost, M. A. (1999). Resilience in adolescents: Protective role of social support, coping strategies, self-esteem, and social activities on experience of stress and depression. Journal of Youth and Adolescence, 28(3), 343-363.

Endler, N. S., \& Parker, J. D. (1990a). Multidimensional assessment of coping: A critical evaluation. Journal of Personality and Social Psychology, 58(5), 844-854. https://doi.org/10.1037/0022-3514. 58.5.844.

Endler, N. S., \& Parker, J. D. (1990b). State and trait anxiety, depression and coping styles. Australian Journal of Psychology, 42(2), 207220. https://doi.org/10.1080/00049539008260119.

Endler, N. S., \& Parker, J. D. (1994). Assessment of multidimensional coping: Task, emotion, and avoidance strategies. Psychological Assessment, 6(1), 50-60. https://doi.org/10.1037/1040-3590.6.1.50.

Fletcher, D., \& Sarkar, M. (2013). Psychological resilience: A review and critique of definitions, concepts, and theory. European Psychologist, 18(1), 12-23. https://doi.org/10.1027/1016-9040/a000124.
Fornell, C., \& Larcker, D. F. (1981). Evaluating structural equation models with unobservable variables and measurement error. Journal of Marketing Research, 18(1), 39-50. https://doi.org/10. 2307/3151312.

Hochwälder, J., \& Saied, V. (2018). The relation between sense of coherence and daily hassles among university students. Health Psychology and Behavioral Medicine, 6(1), 329-339. https://doi. org/10.1080/21642850.2018.1538802.

Hu, L., \& Bentler, P. M. (1999). Cutoff criteria for fit indexes in covariance structure analysis: Conventional criteria versus new alternatives. Structural Equation Modeling: A Multidisciplinary Journal, 6(1), 1-55. https://doi.org/10.1080/10705519909540118.

Jerusalem, M., \& Schwarzer, R. (1992). Self-efficacy as a resource factor in stress appraisal processes. Self-efficacy: Thought control of action, 195213.

Juczyński, Z. (2012). Narzędzia Pomiaru w Promocji i Psychologii Zdrowia. [Tools for measuring stress and coping with stress]. Warszawa: Pracownia Testów Psychologicznych Polskiego Towarzystw Psychologicznego.

Kelly, M. M., Tyrka, A. R., Price, L. H., \& Carpenter, L. L. (2008). Sex differences in the use of coping strategies: Predictors of anxiety and depressive symptoms. Depression and Anxiety, 25(10), 839-846. https://doi.org/10.1002/da.20341.

Kline, R. B. (2015). Principles and practice of structural equation modeling. Guilford Publications.

Krok, D. (2016). Sense of coherence mediates the relationship between the religious meaning system and coping styles in polish older adults. Aging \& Mental Health, 20(10), 1002-1009. https://doi. org/10.1080/13607863.2015.1056772.

Lazarus, R. S., \& Folkman, S. (1984). Stress, appraisal, and coping. Springer Publishing Company.

Luthans, F. (2002). Positive organizational behavior: Developing and managing psychological strengths. Academy of Management Perspectives, 16(1), 57-72. https://doi.org/10.5465/AME.2002.6640181.

Luthar, S. S., Cicchetti, D., \& Becker, B. (2000). The construct of resilience: A critical evaluation and guidelines for future work. Child Development, 71(3), 543-562.

Magnano, P., Craparo, G., \& Paolillo, A. (2016). Resilience and emotional intelligence: Which role in achievement motivation. International Journal of Psychological Research, 9(1), 9-20 ISSN electronic 2011-20799.

Matud, M. P. (2004). Gender differences in stress and coping styles. Personality and Individual Differences, 37(7), 1401-1415. https:// doi.org/10.1016/j.paid.2004.01.010.

Nahlen, C., \& Saboonchi, F. (2010). Coping, sense of coherence and the dimensions of affect in patients with chronic heart failure. European Journal of Cardiovascular Nursing, 9(2), 118-125. https://doi.org/ 10.1016/j.ejcnurse.2009.11.006.

Pallant, J. F., \& Lae, L. (2002). Sense of coherence, well-being, coping and personality factors: Further evaluation of the sense of coherence scale. Personality and Individual Differences, 33(1), 39-48. https:// doi.org/10.1016/S0191-8869(01)00134-9.

Parto, M., \& Besharat, M. A. (2011). The direct and indirect effects of self-efficacy and problem solving on mental health in adolescents: Assessing the role of coping strategies as mediating mechanism. Procedia-Social and Behavioral Sciences, 30, 639-643. https:// doi.org/10.1016/j.sbspro.2011.10.124.

Ptacek, J. T., Smith, R. E., \& Dodge, K. L. (1994). Gender differences in coping with stress: When stressor and appraisals do not differ. Personality and Social Psychology Bulletin, 20(4), 421-430. https://doi.org/10.1177/0146167294204009.

Schwarzer, R. (1993). Measurement of perceived self-efficacy : Psychometric scales for cross-cultural research. Berlin: Freien Universitat.

Shen, Y. E. (2009). Relationships between self-efficacy, social support and stress coping strategies in Chinese primary and secondary 
school teachers. Stress and Health: Journal of the International Society for the Investigation of Stress, 25(2), 129-138. https://doi. org/10.1002/smi.1229.

Smith, G. D., \& Yang, F. (2017). Stress, resilience and psychological well-being in Chinese undergraduate nursing students. Nurse Education Today, 49, 90-95. https://doi.org/10.1016/j.nedt.2016. 10.004 .

Stewart, M., Reid, G., \& Mangham, C. (1997). Fostering children's resilience. Journal of Pediatric Nursing, 12(1), 21-31. https://doi.org/ 10.1016/S0882-5963(97)80018-8

Stratta, P., Capanna, C., Patriarca, S., de Cataldo, S., Bonanni, R. L., Riccardi, I., \& Rossi, A. (2013). Resilience in adolescence: Gender differences two years after the earthquake of L'Aquila. Personality and Individual Differences, 54(3), 327-331. https:// doi.org/10.1016/j.paid.2012.09.016.

Strelau, J., Jaworowska, A., Wrześniewski, K., \& Szczepaniak, P. (2005). Kwestionariusz radzenia sobie $w$ sytuacjach stresowych CISS. [Coping Inventory for Stressful Situations - CISS]. Warszawa: Pracownia Testów Psychologicznych Polskiego Towarzystwa Psychologicznego.

Surzykiewicz, J., Konaszewski, K., \& Wagnild, G. (2019). Polish version of the resilience scale (RS-14): A validity and reliability study in three samples. Frontiers in Psychology, 9. https://doi.org/10.3389/ fpsyg.2018.02762.

Tamres, L. K., Janicki, D., \& Helgeson, V. S. (2002). Sex differences in coping behavior: A meta-analytic review and an examination of relative coping. Personality and Social Psychology Review, 6(1), 2-30. https://doi.org/10.1207/S15327957PSPR0601_1.

Thompson, N. J., Fiorillo, D., Rothbaum, B. O., Ressler, K. J., \& Michopoulos, V. (2018). Coping strategies as mediators in relation to resilience and posttraumatic stress disorder. Journal of Affective Disorders, 225, 153-159. https://doi.org/10.1016/j.jad.2017.08.049.

Wagnild, G. (2009a). A review of the resilience scale. Journal of Nursing Measurement, 17(2), 105-113. https://doi.org/10.1891/1061-3749. 17.2.105.

Wagnild, G. (2009b). The Resilience Scale User's Guide: For the U.S. English Version of the Resilience Scale and the 14-Item Resilience Scale (RS-14). Resilience center.

Wagnild, G. (2014). True resilience: Building a life of strength, courage, and meaning: An interactive guide. Cape House Books.

Wagnild, G., \& Young, H. M. (1990). Resilience among older women. Image: The Journal of Nursing Scholarship, 22(4), 252-255. https:// doi.org/10.1111/j.1547-5069.1990.tb00224.x.

Wagnild, G., \& Young, H. M. (1993). Development and psychometric evaluation of the resilience scale. Journal of Nursing Measurement, 1(2), 165-178.

Publisher's note Springer Nature remains neutral with regard to jurisdictional claims in published maps and institutional affiliations. 